\title{
Sexual Transmission of HIV-1 among Serodiscordant Couples
}

\section{Sandro Vento ${ }^{1}$, Massimiliano Lanzafame ${ }^{2 *}$, Fabiana Corsini ${ }^{2}$ and Emanuela Lattuada ${ }^{2}$}

${ }^{1}$ Department of Internal Medicine, School of Medicine, Faculty of Health Sciences, University of Botswana, Gaborone, Botswana ${ }^{2}$ Unit of Infectious Diseases, "G.B. Rossi" Hospital, Verona, Italy

It has been suggest that although the individual risk of HIV transmission per act is small, the rate of transmission over large numbers of sexual acts could be substantial and influenced by viral load [1]. However, there were some differences, on the cumulative probability of transmission to the serodiscordant partner each year, for female-to-male, male-to-female and male-to-male transmission. We report our own experience of all the HIV-1 infected women followed as outpatients at the Infectious Diseases Unit, G.B. Rossi Hospital, Verona who reported no condom use and had consistently high viral load (due to their refusal of antiretroviral therapy). These 11 heterosexual women have had stable male partners for a mean of 39.7 months (range 12-108 months) and a mean number of 8 vaginal intercourses (range 2-16) per month. All deny anal intercourses. HIVRNA levels have been in all cases higher than 4,000 copies $/ \mathrm{mL}$ in all determinations, and the median viral load has been 22,313 copies $/ \mathrm{mL}$ (range 4,978-124,511). No cases of sexually transmitted diseases have been detected in these patients group or in their male sexual partners throughout the observation period. Interestingly, there have been no cases of HIV-1 transmission to their male sexual partners.
We believe that our results, although obtained in a small cohort, are of interest because they show that female-to-male HIV1 transmission through vaginal intercourse is difficult in the absence of concurrent genital lesions due to sexually transmitted diseases, even when HIVRNA levels are consistently high and antiretroviral therapy is not used. These results, although limited, cast doubts over the widely accepted notion that female-to-male heterosexual transmission is a significant contributor to the HIV1 epidemic in the Western hemisphere [2] and stress the importance of prevention of sexually transmitted diseases [3].

\section{References}

1. Wilson DP, Law MG, Grulich AE, Cooper DA, Kaldor JM (2008) Relation between HIV viral load and infectiousness: a model-based analysis. Lancet 372: 314-320.

2. HIVIAIDS Surveillance in Europe. End-year report 2006. Institut de veille sanitaire, Saint-Maurice.

3. Galvin SR, Cohen MS (2004) The role of sexually transmitted diseases in HIV transmission. Nat Rev Microbiol 2: 33-42.
${ }^{*}$ Corresponding author: Massimiliano Lanzafame, Unit of Infectious Diseases, "G.B. Rossi" Hospital, Verona, via Strada Romana 11, San Bonifacio (VR), CAP 37047, Italy, Tel: 0039-0458128256; Fax: 0039-0458128257; E-mail: lanzafame.massimiliano@gmail.com

Received October 22, 2012; Published October 26, 2012

Citation: Vento S, Lanzafame M, Corsini F, Lattuada E (2012) Sexual Transmission of HIV-1 among Serodiscordant Couples. 1:398. doi:10.4172/scientificreports.398

Copyright: (C) 2012 Vento S, et al. This is an open-access article distributed under the terms of the Creative Commons Attribution License, which permits unrestricted use, distribution, and reproduction in any medium, provided the original author and source are credited. 